\title{
Effects of an Early Weaning on Phosphate Transport Maturation in the Rat Kidney: Influence of the Phosphate Content of the Diet
}

\author{
MARTINE LELIEVRE-PEGORIER, BRUNO LEROY, EVELYNE MOREAU, \\ LILIANE HERPE-PATSOURIS, AND CLAUDIE MERLET-BENICHOU \\ Unité de Recherches sur le Développement Normal et Pathologique des Fonctions Epithéliales, INSERM U319, \\ Université Paris 7, Paris, France
}

\begin{abstract}
The renal phosphate (Pi) transport system matures during the 3rd postnatal wk in the rat by an increase in the carrier affinity for sodium-cotransported phosphate. This study examines the ability of pups to adapt their renal $\mathrm{Pi}$ transport to the dietary phosphorus content during this period of carrier affinity maturation, corresponding to the weaning period in the rat. Clearance experiments and brush border membrane studies were performed on 21-d-old rats weaned early on d 16 onto a low phosphate diet (LPD, $0.19 \mathrm{~g} / 100 \mathrm{~g}$ ), a normal phosphate diet (control, $0.78 \mathrm{~g} / 100 \mathrm{~g}$ ), or a high phosphate diet (HPD, $1.5 \mathrm{~g} / 100 \mathrm{~g})$. In LPD rats, the Pi fractional excretion $(0.3 \pm 0.1 \%)$ was lower than in controls $(18 \pm 3 \%$, $p<0.001)$. It remained very low $(0.21 \pm 0.05 \%$ in LPD rats versus $40.5 \pm 6.3 \%$ in controls, $p<0.001$ ) after $\mathrm{Pi}$ perfusion $\left(1.5 \mu \mathrm{mol} \cdot \mathrm{min}^{-1} \cdot 100 \mathrm{~g}^{-1}\right)$ and the reabsorbed $\mathrm{Pi}$ per min, corrected for the glomerular filtration rate, was higher than in the two other groups. The calcium fractional excretion $(12.6 \pm 1.02 \%)$ in the LPD rats was much higher than in the controls $(0.42 \pm 0.2 \%, p<0.001)$. In contrast, HPD rats had an elevated Pi fractional excretion (41 \pm $4 \%, p<0.001$ ), whereas reabsorbed phosphate per min corrected for the glomerular filtration rate was not increased by a Pi load. The membrane vesicles from 21 -dold LPD rats had a higher $V_{\max }(11466 \pm 1840 \mathrm{pmol} \cdot \mathrm{mg}$ protein $\left.^{-1} \cdot 10 \mathrm{~s}^{-1}\right)$ than the controls $(7019 \pm 1112 \mathrm{pmol}$. mg protein $\left.{ }^{-1} \cdot 10 \mathrm{~s}^{-1}, p<0.01\right)$, whereas those from HPD rats had a lower $V_{\max }(5161 \pm 956, p<0.01)$. The apparent $\mathrm{Km}$ values were unchanged. The LPD rats had high plasma calcium levels. The parathyroid hormone level was depressed by this hypercalcemia $[21.97 \pm 1.9 \mathrm{pg} / \mathrm{mL}(2.31 \pm$ $0.2 \mathrm{pmol} / \mathrm{L})$ in LPD and $38.54 \pm 2.01 \mathrm{pg} / \mathrm{mL}(4.05 \pm 0.21$ $\mathrm{pmol} / \mathrm{L}$ ) in normal $\mathrm{Pi}$ diet rats, $n=8, p<0.001]$. This plus their LPD explains the lower Pi fractional excretion of these rats and the low $\mathrm{Pi} \mathrm{V}_{\max }$ in their brush border membrane. The plasma parathyroid hormonal level of HPD rats was normal $[35.07 \pm 2.23 \mathrm{pg} / \mathrm{mL}(3.69 \pm 0.23$ $\mathrm{pmol} / \mathrm{L}), n=8$ ]. We conclude that the young 3 -wk-old rat can adapt its renal Pi transport capacity to the dietary phosphorus content during the weaning period by varying the number of functional units of the sodium Pi cotransporter or by increasing its turnover rate. Changing the $\mathbf{P i}$ content of the diet induces no apparent change in Pi transport maturation during this period, as there was no change in the carrier affinity. (Pediatr Res 32: 704-709, 1992)
\end{abstract}

Reccived November 21, 1991 ; accepted July 21, 1992.

Correspondence: Dr. M. Lelievre-Pegorier, INSERM U319, Université Paris 7 , 2. place Jussieu, 75251 Paris, France.

\section{Abbreviations}

Pi, phosphate

LPD, low phosphate diet

HPD, high phosphate diet

NPD, normal phosphate diet

PiR, phosphate reabsorption

GFR, glomerular filtration rate

PTH, parathyroid hormone

BBM, brush border membrane

FE, fractional excretion

QR, quantity reabsorbed

PCT, proximal convoluted tubule

HEPES, $N$-2-hydroxyethylpiperazine- $N^{\prime}-2$ -

ethanesulfonic acid

Animal studies have shown that the renal tubule of the adult rat is able to change its capacity to transport inorganic $\mathrm{Pi}$ in response to dietary $\mathrm{Pi}(1-3)$. Under these conditions, tubular transport of $\mathrm{Pi}$ is controlled by a PTH-independent mechanism that responds to changes in the Pi uptake. Several authors have shown that young growing rats, about 2 mo old, can also adapt to a low $\mathrm{Pi}$ intake by changing tubular $\mathrm{Pi}$ reabsorption $(4,5)$. Mulroney and Haramati (6) have shown that young weaned rats are hypersensitive to $\mathrm{Pi}$ deprivation and moderately resistant to the phosphaturic effects of high dietary $\mathrm{Pi}$ intake. The high rate of $\mathrm{Pi}$ transport in the kidney of developing rats and the adaptation to an increase in Pi supply are likely to be independent of the effects of PTH. The Pi transport rate in guinea pigs, evaluated in BBM, is very high and does not increase on an LPD (7). However, the effects of changes in Pi supply in all these studies on rats and guinea pigs were tested after the system had matured.

The question is therefore whether the Pi transport system can adapt before it matures. The sodium-dependent Pi transport increases during the $3 \mathrm{rd}$ postnatal wk in the rat, as the result of an increase in the affinity of the carrier for $\mathrm{Pi}(8)$. The present work was carried out to determine the Pi transport capacity of 21-d-old rats weaned early, on d 16, onto normal, low, and high $\mathrm{Pi}$ diets. The capacity was measured in vivo by clearance experiments. The circulating level of immunoreactive PTH was also measured. Changes in the kinetics parameters of $\mathrm{Pi}$ transport were checked using BBM isolated from young rats weaned early onto the same diet.

\section{MATERIALS AND METHODS}

Animals. Pregnant Sprague-Dawley rats were housed individually and maintained on a standard laboratory diet (A03, UAR, Epinay sur Orge, France, containing $0.8 \mathrm{~g} / 100 \mathrm{~g} \mathrm{Pi}$ ) with water 
Table 1. Body weight, kidney weight, GFR, plasma Pi ([Pi]), amount of Pi filtered ([Pi].GFR), FE \% Pi, and reabsorbed phosphate per min corrected for GFR (RQ Pi/GFR) in 21-d-old rats weaned early on d 16 onto low, normal, or high Pi diets*

\begin{tabular}{|c|c|c|c|c|c|c|c|c|c|}
\hline Diet & $\begin{array}{c}\mathrm{Pi} \\
(\mathrm{g} / 100 \mathrm{~g})\end{array}$ & $\begin{array}{l}\text { Body } \\
\text { weight } \\
\text { (g) }\end{array}$ & $\begin{array}{c}\text { Kidney } \\
\text { weight } \\
\text { (mg) }\end{array}$ & Period & $\begin{array}{c}\text { GFR } \\
(\mu \mathrm{L} / \min )\end{array}$ & $\begin{array}{c}{[\mathrm{Pi}]} \\
(\mathrm{mmol} / \mathrm{L})\end{array}$ & $\begin{array}{c}{[\mathrm{Pi}] \cdot \mathrm{GFR}} \\
(\mu \mathrm{mol} / \mathrm{min})\end{array}$ & $\mathrm{FE} \% \mathrm{Pi}$ & $\begin{array}{c}\text { RQ Pi/GFR } \\
(\mu \mathrm{mol} / \mathrm{mL})\end{array}$ \\
\hline \multirow{2}{*}{$\operatorname{LPD}(n=6)$} & \multirow{2}{*}{0.19} & \multirow[t]{2}{*}{$49 \pm 1$} & \multirow{2}{*}{$315 \pm 11$} & 1 & $138 \pm 12$ & $2.47 \pm 0.06 \dagger$ & $341 \pm 30 \ddagger$ & $0.34 \pm 0.10 \dagger$ & $2.47 \pm 0.06$ \\
\hline & & & & 2 & $195 \pm 15 \S$ & $3.05 \pm 0.15+\S$ & $591 \pm 31 \|$ & $0.21 \pm 0.05 \dagger$ & $3.07 \pm 0.16 \neq \|$ \\
\hline \multirow[t]{2}{*}{$\operatorname{NPD}(n=6)$} & \multirow[t]{2}{*}{0.78} & \multirow{2}{*}{$53 \pm 2$} & \multirow{2}{*}{$369 \pm 15$} & 1 & $151 \pm 12$ & $3.26 \pm 0.09$ & $492 \pm 43$ & $17.7 \pm 2.6$ & $2.70 \pm 0.14$ \\
\hline & & & & 2 & $193 \pm 17 \|$ & $3.76 \pm 0.12 \|$ & $728 \pm 67 \|$ & $40.5 \pm 6.3 \|$ & $2.29 \pm 0.20$ \\
\hline \multirow{2}{*}{$\operatorname{HPD}(n=6)$} & \multirow[t]{2}{*}{1.5} & \multirow[t]{2}{*}{$54 \pm 1$} & \multirow[t]{2}{*}{$382 \pm 18$} & 1 & $224 \pm 10 \dagger$ & $2.49 \pm 0.09 \dagger$ & $553 \pm 30$ & $41.3 \pm 4.1 \dagger$ & $1.49 \pm 0.13 \dagger$ \\
\hline & & & & 2 & $221 \pm 18$ & $3.03 \pm 0.18 \| \boldsymbol{q}$ & $660 \pm 44$ & $45.4 \pm 5.1$ & $1.61 \pm 0.15 \ddagger$ \\
\hline
\end{tabular}

* Physiologic saline was perfused at $30 \mu \mathrm{L} / \mathrm{min} / 100 \mathrm{~g}$ body weight during period 1 (mean of two clearance periods of $30 \mathrm{~min}$ each); $1.5 \mu \mathrm{mol} /$ $\mathrm{min} / 100 \mathrm{~g} \mathrm{Pi}$ were added to the perfused solution during period 2 (mean of two clearance periods of $30 \mathrm{~min}$ ). $n$ is the number of rats.

$+p<0.001$ compared to NPD rats.

$\mp p<0.05$ compared to NPD rats.

$\$ p<0.01$ period 2 compared to period 1 in each group.

$\| p<0.05$ period 2 compared to period 1 in each group.

I $p<0.01$ compared to NPD rats.

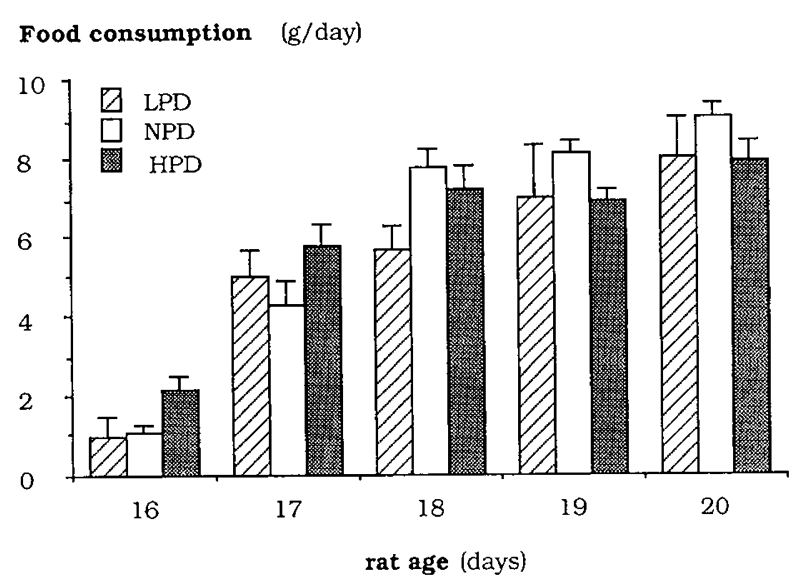

(a)

Phosphate consumption (mg/day)

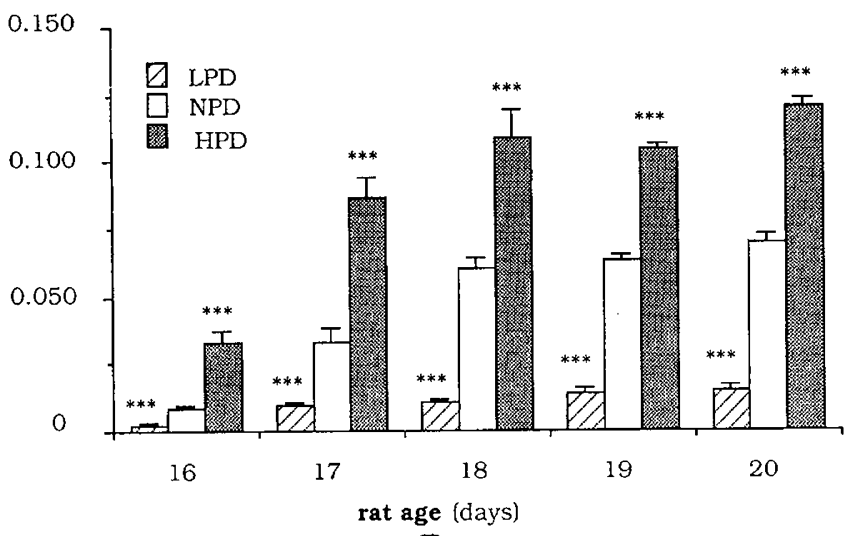

(b)

Fig. 1. Daily food $(a)$ and phosphorus $(b)$ consumption of earlyweaned rats from d 16 to d 21 on LPD, NPD, and HPD.

ad libitum throughout gestation. They were allowed to deliver spontaneously. All litters were reduced to eight pups at birth. The pups were kept with their mothers under normal conditions until d 16, when they were divided in three groups and weaned early onto laboratory food containing $0.78 \mathrm{~g} / 100 \mathrm{~g}$ Pi for the NPD, $0.19 \mathrm{~g} / 100 \mathrm{~g}$ Pi (LPD), or $1.5 \mathrm{~g} / 100 \mathrm{~g} \mathrm{Pi}$ (HPD). The daily food and $\mathrm{Pi}$ intakes were determined in all three groups of rats. Experiments were carried out on 21 -d-old rats.

Clearance experiments. Six pups from each group, taken from six litters, were used for clearance experiments, which always started at the same time in the morning. They were anesthetized with an intraperitoneal injection of $100 \mathrm{mg} \cdot \mathrm{kg}^{-1}$ body weight Inactin (Byk Gulden Pharmaceutical, Konstanz, Germany) and placed on a heated table to maintain their body temperature at $37-38^{\circ} \mathrm{C}$. Tracheotomy was performed, but the thyroid gland was left intact. Polyethylene catheters (PE 50, Intramedic ClayAdams, Parsippany, NJ) were inserted into the right external jugular vein for infusion, the right femoral artery for monitoring blood pressure and blood sampling, and the two ureters for urine collection. After surgery, the rats were infused with saline $(1.3 \%$ of body weight) and given a priming dose of ${ }^{3} \mathrm{H}$-inulin (New England Nuclear, sp act $8.5 \mathrm{GBq} / \mathrm{g}$ ), followed by an appropriate sustaining dose of the marker in saline solution, perfused at 30 $\mu \mathrm{L} \cdot \mathrm{min}^{-1} \cdot 100 \mathrm{~g}^{-1}$ throughout the experiment. After a $1-\mathrm{h}$ equilibration, urine was continuously collected from each animal for two 30 -min periods. The perfusing solution was then replaced by the same solution containing Pi for a final delivery of 1.5 $\mu \mathrm{mol} \cdot \mathrm{min}^{-1} \cdot 100 \cdot \mathrm{g}^{-1}$. This solution contained mono- and disodium $\mathrm{Pi}$ to obtain a $\mathrm{pH}$ of 7.4. After an equilibration period of 30 min, urine was collected for two additional 30-min periods. Arterial blood was sampled for each period and immediately centrifuged. The plasma was kept for analysis. The erythrocytes were suspended in an equal volume of normal saline and reinjected at the end of the period. Arterial blood pressure was constant throughout the experiment. At the end of the experiment, the two kidneys were removed and weighed. The ${ }^{3} \mathrm{H}$-inulin concentrations in the plasma and urine samples were determined by liquid scintillation in Instagel solution (Packard, Downers Grove, IL). The Pi concentration was measured according to Chen et al. (9), and the sodium, magnesium, and calcium concentrations were determined with an atomic fluorescence spectrometer (Baird, Bedford, MA). The fractional urinary excretions of calcium and magnesium were calculated, assuming an ultrafilterability of 0.68 for calcium and 0.86 for magnesium, as specified by Bailly and Amiel (10).

$B B M$ isolation and transport measurement. Rat renal BBM vesicles were prepared by the calcium precipitation method (11). The kidneys from 24 NPD rats and 24 LPD or HPD rats aged $21 \mathrm{~d}$ were used for each experiment. The kidney cortical tissue was dissected out and treated by the method of Evers et al. (12) as modified by Jean et al. (13). The quality of the final BBM preparations was evaluated by enzyme markers. Pi uptake was measured at room temperature by the filtration technique (14). All experiments were conducted in the presence of a sodium or potassium gradient. The final membrane buffer contained 100 $\mathrm{mM}$ mannitol and $20 \mathrm{mM}$ HEPES-Tris ( $\mathrm{pH} 7.4$ ). All solutions were filtered (Millipore filter) before use. The incubation solution contained $100 \mathrm{mM}$ mannitol, $100 \mathrm{mM} \mathrm{NaCl}, 20 \mathrm{mM}$ HEPESTris ( $\mathrm{pH} 7.4$ ), and ${ }^{32} \mathrm{P}$-sodium-Pi (CEA, Saclay, France, sp act 
Table 2. Plasma calcium ([Ca]), FE of calcium (FE\% Ca), plasma sodium ([Na]), FE of sodium (FE \% Na), plasma magnesium ([Mg]), and FE of magnesium (FE\% Mg) in 21-d-old animals weaned early on d 16 onto low, normal, or high Pi diets*

\begin{tabular}{|c|c|c|c|c|c|c|c|c|}
\hline Diet & $\begin{array}{c}\mathrm{Pi} \\
(\mathrm{g} / 100 \mathrm{~g})\end{array}$ & Period & $\begin{array}{c}{[\mathrm{Ca}]} \\
(\mathrm{mmol} / \mathrm{L})\end{array}$ & $\mathrm{FE} \% \mathrm{Ca}$ & $\begin{array}{c}{[\mathrm{Na}]} \\
(\mathrm{mmol} / \mathrm{L})\end{array}$ & $\mathrm{FE} \% \mathrm{Na}$ & $\begin{array}{c}{[\mathrm{Mg}]} \\
(\mathrm{mmol} / \mathrm{L})\end{array}$ & $\mathrm{FE} \% \mathrm{Mg}$ \\
\hline \multirow[t]{2}{*}{$\operatorname{LPD}(n=6)$} & 0.19 & 1 & $3.43 \pm 0.13 \dagger$ & $12.6 \pm 1.0 \neq$ & $139.3 \pm 1.2$ & $0.31 \pm 0.03 \S$ & $0.6 \pm 0.03 \dagger$ & $23.4 \pm 4.2$ \\
\hline & & 2 & $3.15 \pm 0.15$ & $11.6 \pm 1.3 \ddagger$ & $141.8 \pm 1.8$ & $0.25 \pm 0.05$ & $0.56 \pm 0.03 \dagger$ & $15.9 \pm 1.4$ \\
\hline \multirow[t]{2}{*}{$\operatorname{NPD}(n=6)$} & 0.78 & 1 & $2.69 \pm 0.11$ & $0.42 \pm 0.2 i$ & $142.4 \pm 1.5$ & $0.08 \pm 0.03$ & $0.76 \pm 0.02$ & $30.6 \pm 3.8$ \\
\hline & & 2 & $2.76 \pm 0.09$ & $0.21 \pm 0.03$ & $139.5 \pm 1.6$ & $0.27 \pm 0.09$ & $0.69 \pm 0.02$ & $23.4 \pm 4.4$ \\
\hline \multirow[t]{2}{*}{$\operatorname{HPD}(n=6)$} & 1.5 & 1 & $3.02 \pm 0.13$ & $0.31 \pm 0.06$ & $139.6 \pm 1.3$ & $0.19 \pm 0.06$ & $0.71 \pm 0.07$ & $38.1 \pm 11.9$ \\
\hline & & 2 & $3.03 \pm 0.23$ & $0.31 \pm 0.07$ & $143.8 \pm 1.6$ & $0.53 \pm 0.15 \|$ & $0.74 \pm 0.03$ & $27.6 \pm 4.9$ \\
\hline
\end{tabular}

* Physiologic solution was perfused at $30 \mu \mathrm{L} / \mathrm{min} / 100 \mathrm{~g}$ body weight during period 1 (mean of two 30 -min clearance periods); $1.5 \mu \mathrm{mol} / \mathrm{min} / 100$ $\mathrm{g} \mathrm{Pi}$ were added to the perfused solution during period 2 (mean of two clearance periods of $30 \mathrm{~min}$ ). $n$ is the number of rats.

$\uparrow p<0.01$ compared to NPD rats.

$\ddagger p<0.001$ compared to NPD rats.

$\S p<0.05$ compared to NPD rats.

$\| p<0.05$ period 2 compared to period 1 in each group.

Table 3. Serum PTH concentration in NPD, LPD, and HPD rats*

\begin{tabular}{cccc}
\hline \multicolumn{4}{c}{ Nats $^{*}$} \\
\hline NPD & LPD & HPD \\
\hline PTH $(\mathrm{pg} / \mathrm{mL}) \dagger(n=10)$ & $38.5 \pm 2.0$ & $22.0 \pm 1.9 \ddagger$ & $35.1 \pm 2.2$ \\
\hline
\end{tabular}

$*$ Values are means \pm SEM for 10 determinations.

$\uparrow$ Conversion factor to SI units: $1 \mathrm{pg} / \mathrm{mL}=0.1053 \mathrm{pmol} / \mathrm{L}$

$\$ p<0.001$ vs NPD group.

$7400 \mathrm{GBq} / \mathrm{mg}$ ). Uptake was initiated by adding $5 \mu \mathrm{L}$ of BBM suspension (about $10 \mathrm{mg}$ protein $/ \mathrm{mL}$ ) to $50 \mu \mathrm{L}$ of incubation medium. After $10 \mathrm{~s}$, the suspension was diluted by adding $2 \mathrm{~mL}$ ice-cold stop solution (100 mM mannitol, $150 \mathrm{mM} \mathrm{NaCl}, 20$ $\mathrm{mM}$ HEPES-Tris $\mathrm{pH} 7.4,10 \mathrm{mM}$ arsenate), filtered through a $0.45-\mu \mathrm{m}$ Sartorius filter, and washed three times with $3 \mathrm{~mL}$ ice cold stop solution. All incubations were carried out in triplicate. For the time-course experiments, $30 \mu \mathrm{L}$ of BBM vesicle suspension was mixed with $320 \mu \mathrm{L}$ of incubation medium. Aliquots $(40 \mu \mathrm{L})$ were removed at 15 and $30 \mathrm{~s}$, and $1,2,5,20$, and 60 min, and filtered as described above. Correction for nonspecific binding to the dried filters was made by subtracting the blank value, obtained by filtering incubation medium without vesicles, from all data. The radioactivity of the dried filters was determined by liquid scintillation counting (LKB Instruments Inc., Rockville, MD) in Instagel solution (Packard).

Enzyme assays. The activities of maltase and alkaline phosphatase, the marker enzymes for BBM vesicles, and $\mathrm{Na}^{+}-\mathrm{K}^{+}$. ATPase and glucose-6-phosphatase, the marker enzymes for the basolateral plasma membrane and endoplasmic reticulum, respectively, were measured. Maltase activity was assayed by the method of Dahlquist (15) with maltose as substrate. Samples were incubated in 0.60 to $20 \mathrm{mM}$ maltose and $50 \mathrm{mM}$ acetate buffer, $\mathrm{pH} 6.0$, at $37^{\circ} \mathrm{C}$. The reaction was started by adding 100 $\mu \mathrm{L}$ diluted $\mathrm{BBM}$ vesicles $(0.60 \mu \mathrm{g}$ protein $/ \mathrm{mL})$ to $300 \mu \mathrm{L}$ maltosebuffer mixture and was terminated after $30 \mathrm{~min}$ by adding 40 $\mu \mathrm{L}$ cold $8 \%$ perchloric acid. The glucose released was measured as described by Bergmeyer (16). Alkaline phosphatase activity was determined according to Hübsher and West (17) using p-nitrophenyl phosphate as substrate. $\mathrm{Na}^{+}-\mathrm{K}^{+}$-ATPase and glucose-6-phosphatase were assayed by the methods of Quigley and
Gotterer (18) and Hübsher and West (17). Protein was measured according to Bradford (19) using BSA as the reference.

Serum PTH concentration. Serum PTH concentration was measured with an intact $\mathrm{NH}_{2}$-terminal-specific PTH RIA (Nichols Institute Diagnostics, San Juan Capistrano, CA). The intact $\mathrm{NH}_{2}$-terminal-specific PTH RIA kit contains chicken antiPTH serum directed against the 1-34 region of PTH, h-PTH-(134) standards, goat antichicken gamma globulin precipitating antibody, and ${ }^{125}$ I-bovine PTH-(1-84) as tracer. The use of this kit for measuring rat PTH has been validated by others $(20,21)$. All measurements were made in duplicate on $300 \mu \mathrm{L}$ of rat serum stored at $-20^{\circ} \mathrm{C}$.

Statistics. All values are means \pm SEM. The clearance data for the NPD, LPD, and HPD rats were compared by $t$ test and variance analysis. The BBM vesicles data for the LPD and HPD rats and their corresponding NPD rats were compared by paired $t$ test. The paired $t$ test was used to take into account variations due to experimental procedure, because the kidneys of control rats were compared to the kidneys of one of the treated groups (HPD or LPD rats) in each experiment (BBM vesicle preparation and kinetics).

\section{RESULTS}

Animals. The body weight gain of the NPD rats between 16 and $21 \mathrm{~d}$ was similar to that of normal pups not separated from their mother. The body weights of young NPD and normal rats were $37 \pm 3 \mathrm{~g}$ and $38 \pm 0.5 \mathrm{~g}$ on $\mathrm{d} 16$, respectively, and $53 \pm 2$ $\mathrm{g}$ and $53 \pm 0.5 \mathrm{~g}$ on $\mathrm{d} 21,(n=6)$. The body weights of the NPD, LPD, and HPD rats on $\mathrm{d} 21$ were essentially the same (Table 1).

Figure 1 shows the daily food and $\mathrm{Pi}$ consumption. The Pi consumption was correlated with the Pi content of the diet, whereas the food consumption was similar in all three groups of rats.

Clearance Experiments. The means of the clearance data before (basal status) and after Pi perfusion are given in Table 1.

Basal data (period 1). The plasma Pi of the LPD rats was significantly lower than that of the NPD rats and their GFR were similar, whereas the Pi filtered load of the LPD rats was

Table 4. Enrichment factors of marker enzymes in kidney homogenates and BBM vesicles isolated from NPD and LPD rats and from NPD and HPD rats*

\begin{tabular}{lrrrr}
\hline \multicolumn{1}{c}{ Enzymes } & \multicolumn{4}{c}{ Enrichment factors } \\
\cline { 2 - 5 } \multicolumn{1}{c}{ NPD1 } & \multicolumn{1}{c}{ LPD } & \multicolumn{1}{c}{ NPD2 } & HPD \\
\hline Maltase $(n=6)$ & $10.73 \pm 0.91$ & $11.08 \pm 0.72$ & $10.00 \pm 1.10$ & $11.11 \pm 0.73$ \\
Alkaline phosphatase $(n=6)$ & $9.88 \pm 0.53$ & $8.60 \pm 0.98$ & $8.30 \pm 0.62$ & $9.20 \pm 0.55$ \\
Glucose-6-phosphatase $(n=6)$ & $0.10 \pm 0.03$ & $0.09 \pm 0.02$ & $0.78 \pm 0.29$ & $0.50 \pm 0.26$ \\
$\mathrm{Na}^{+}-\mathrm{K}^{+}$-ATPase $(n=6)$ & $2.32 \pm 0.40$ & $1.60 \pm 0.23$ & $1.60 \pm 0.50$ & $2.70 \pm 0.40$ \\
\hline
\end{tabular}

\footnotetext{
$*$ Values are means \pm SEM for $n$ experiments in each group. Each experiment pooled kidneys of 24 animals.
} 
Phosphate uptake

(\% of equilibrium)

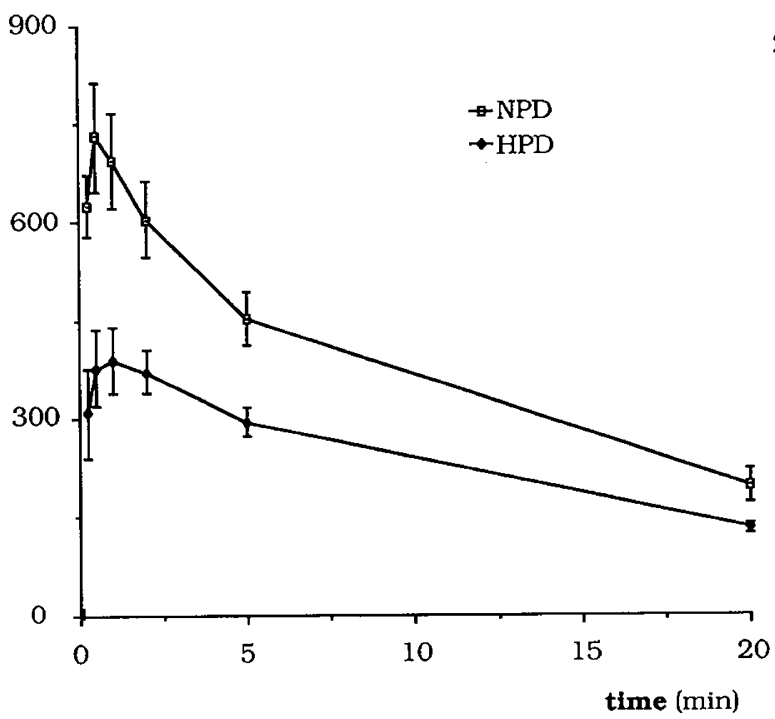

(a)
Phosphate uptake

(\% of equilibrium)

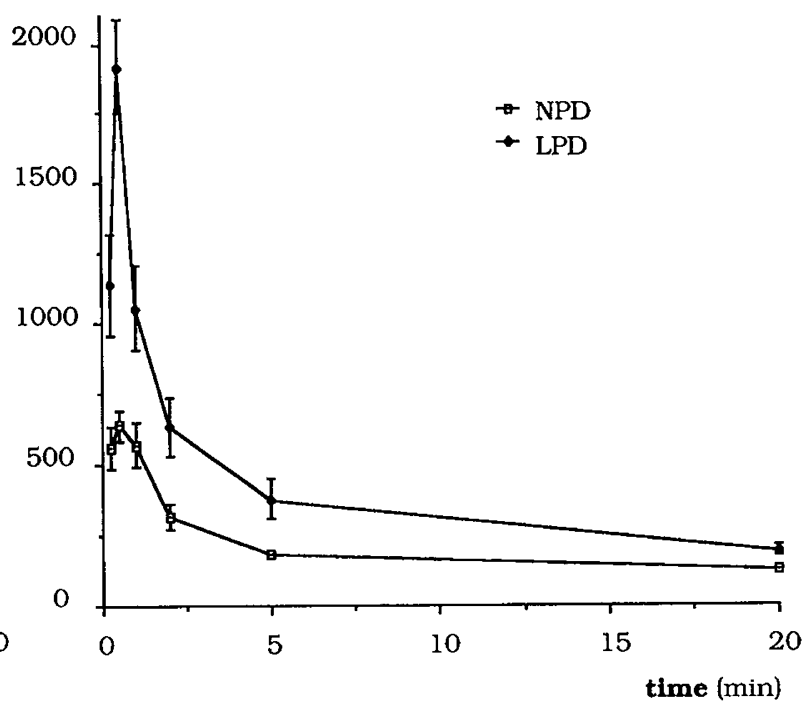

(b)

Fig. 2. Time-course of Pi uptake by isolated renal brush border vesicles. Open squares and black diamonds represent Pi uptake in renal brush border vesicles isolated from NPD and HPD rats $(a)$ and NPD and LPD rats $(b)$, respectively.

significantly lower. The LPD rats also had a very low FE \% of Pi (Table 1).

The HPD rats also had a lower plasma Pi than the NPD rats. However, a concomittant increase in GFR resulted in a similar Pi filtered load. The Pi FE of HPD rats was very high (Table 1).

Table 2 shows the data for other ions. The plasma calcium of LPD was higher than in NPD rats; this hypercalcemia was accompanied by a large increase in the FE of calcium. The FE of sodium was above normal in LPD and HPD rats, but the difference was significant only in LPD rats. The plasma magnesium was lower in LPD rats, with no change in the FE of this ion.

After Pi perfusion (period 2). The plasma Pi and GFR of LPD rats increased significantly (Table 1 ). The Pi FE remained lower than in the other groups. The Pi transport capacity (QR Pi/GFR) increased significantly and became higher than that of the other groups (Table 1).

The plasma Pi and GFR of the NPD rats increased significantly. The Pi transport capacity remained the same, and the FE of $\mathrm{Pi}$ increased significantly.

The plasma Pi also increased significantly in the HPD rats. Neither the Pi filtered load nor the Pi transport capacity was altered by the $\mathrm{Pi}$ infusion.

The plasma calcium was no longer above normal in LPD rats after $\mathrm{Pi}$ perfusion. The $\mathrm{Pi}$ perfusion induced increases in the FE of sodium in NPD and HPD rats, so that there was no difference among the three groups. Plasma magnesium remained low in the LPD rats, but the FE \% was similar in all three groups (Table 2).

The serum PTH concentrations in these rats are summarized in Table 3. The PTH level in LPD rats was significantly lower than in NPD and HPD rats.

$B B M$ Studies. Enzymes were routinely used to check the purity of the membrane preparations. Table 4 shows the enrichment factors in BBM vesicles of maltase, alkaline phosphatase, $\mathrm{Na}^{+}$$\mathrm{K}^{+}$-ATPase, and glucose-6-phosphatase. The sp act of these enzymes were not significantly different in the two groups of rats and their corresponding controls, nor was the enrichment of brush border enzymes over the homogenate activity (Table 4). This indicates that the quality of the membrane preparations was not different. These enrichment factors were similar to those reported for mature rat $\mathrm{BBM}$ vesicles prepared by the same method (12). These results, plus the virtual absence of contamination by basolateral or endoplasmic reticulum membranes, confirm the purity of the membrane preparations.

$\mathrm{Pi}$ uptake by the BBM vesicles of 21 -d-old rats was rapid at $0.12 \mathrm{mM} \mathrm{Pi}$, with an overshoot phenomenon, and reached a maximal value at $1 \mathrm{~min}$ in all groups (Fig. 2). The initial rate of $\mathrm{Pi}$ entry into the vesicles of LPD rats and the maximal intravesicular content were about $74 \%$ greater than that of controls. Conversely, it was about $57 \%$ lower in HPD rats than in controls. However, the same equilibrium values were reached at $60 \mathrm{~min}$. The overshoot was abolished in the absence of a sodium gradient, when sodium chloride was replaced by potassium chloride in the incubation medium, and the Pi uptakes of LPD rats and their controls, and HPD and their controls, were very similar although much reduced.

The kinetics of Pi transport as a function of the Pi concentration in the vesicle incubation medium was studied by measuring $\mathrm{Pi}$ uptake at $10 \mathrm{~s}$ for $\mathrm{Pi}$ concentrations of 0.1 to $2.95 \mathrm{mM}$. Because Pi uptake was linear up to $15 \mathrm{~s}$, the 10 -s value was chosen for comparing the various groups of rats. The sodiumindependent influx component was estimated by replacing sodium chloride with potassium chloride. After removal of this component, the kinetic parameters were calculated from HanesWoolf plots (S/V versus $S$, where $S$ is the substrate concentration and $\mathrm{V}$ is the intravesicular $\mathrm{Pi}$ uptake per min per $\mathrm{mg}$ protein) (Fig. 3). In each of the six series of experiments, the $V_{\max }$ value was lower in HPD than in control rats and was higher in LPD rats than in their controls, whereas the apparent $\mathrm{Km}$ values were very similar (Table 5).

\section{DISCUSSION}

The data reported here show that early weaned rats can adapt their PiR capacity to the Pi content of the diet during the 3rd postnatal wk, when carrier affinity matures.

Clearance data. The PiR capacity of adult rats varies in response to a change in $\mathrm{Pi}$ intake, and this phenomenon persists in thyroparathyroidectomized rats $(1,2,22)$. PiR also increases when growing weaned rats are placed on an LPD $(4,5)$. As in the adult, the response to change in $\mathrm{Pi}$ diet persists when the animals are thyroparathyroidectomized (6).

The pups used in this study were weaned early, on $\mathrm{d} 16$, onto 
Table 5. Kinetic parameters of Pi transport in renal BBM vesicles from 21 -d-old LPD and HPD rats and the corresponding NPD rats*

\begin{tabular}{|c|c|c|c|c|}
\hline & NPDI & LPD & NPD2 & HPD \\
\hline $\mathrm{V}_{\max }(\mathrm{pmol} / \mathrm{mg}$ protein $/ 10 \mathrm{~s})(n=6)$ & $7019 \pm 1112$ & $11466 \pm 1840 \dagger$ & $7248 \pm 1946$ & $5161 \pm 956 \dagger$ \\
\hline $\mathrm{K}_{\mathrm{m}}(\mathrm{mM})(n=6)$ & $0.24 \pm 0.03$ & $0.22 \pm 0.03$ & $0.22 \pm 0.05$ & $0.25 \pm 0.07$ \\
\hline
\end{tabular}

* Values are means \pm SEM for $n$ experiments in each group. Each experiment pooled kidneys of 24 animals.

$\dagger p<0.05 v$ s controls.

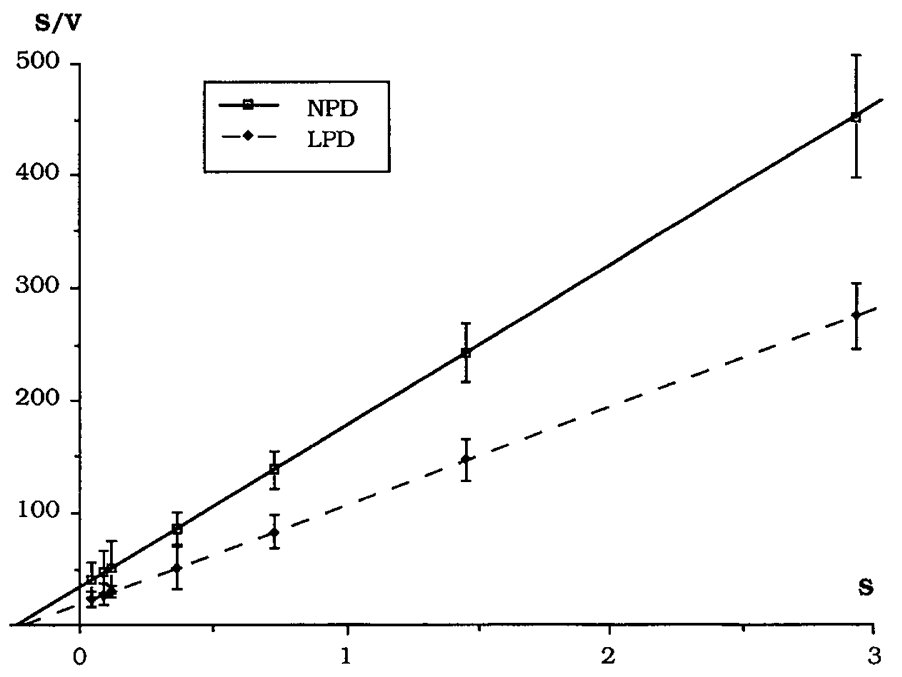

(a)

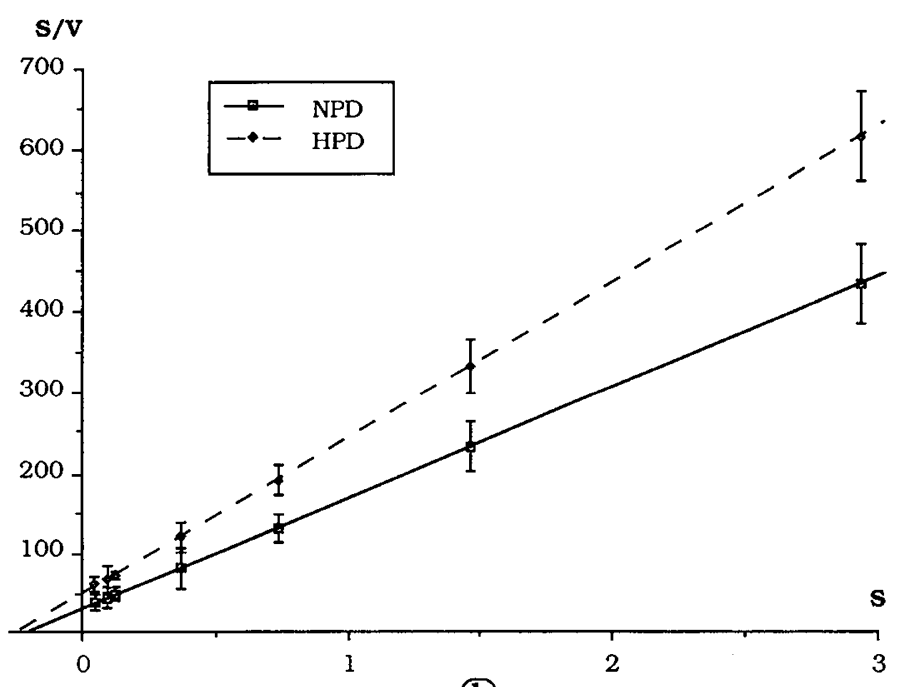

(b)

Fig. 3. Hanes-Woolf plots of sodium-dependent Pi influx into BBM vesicles obtained from NPD (solid line) and LPD (dashed line) rats (a) and NPD (solid line) and HPD (dashed line) rats $(b)$, respectively. $S, P \mathbf{i}$ concentration in incubation medium; $V$, intravesicular Pi uptake per min per $\mathrm{mg}$ protein.

diets with different Pi contents. The data for 21-d-old rats fed an LPD or an HPD were compared with those for rats on an NPD. Estimations of the daily food intake indicate that the rats were not subjected to starvation during the days before the experiments, which would have induced a decrease in the renal Pi transport (23), and that the food intakes of all groups were similar, although the Pi intakes were significantly different.

In the LPD rats, the basal FE of $\mathrm{Pi}$ was much lower than that of controls; nevertheless, their Pi filtered load was lower and the $\mathrm{Pi} \mathrm{QR} / \mathrm{min}$, corrected for GFR, was not different from that of controls. The Pi transport capacity is closely correlated with GFR. It was therefore expressed in terms of GFR to remove the contribution of GFR to its variation (24). The reabsorption capacity of rats on the LPD increased when the Pi-filtered load was increased by Pi perfusion. The maximal transport was not reached in the basal state, as was indicated by the increase in Pi QR/GFR after the Pi load. In agreement with the reports of Caverzasio et al. (4) and Karlen (5) on 2-mo-old rats, the plasma $\mathrm{Pi}$ of early weaned 21-d-old rats fed an LPD was higher than that of adult rats, although it was lower than that of control rats of the same age. Pi depletion, which is accompanied by the release of calcium and $\mathrm{Pi}$ from bone, may explain the maintained phosphatemia (25). The elevated plasma calcium in LPD rats may reflect this increase in bone resorption. It may explain the decrease in PTH level and hence the lower Pi FE observed. The high calciuria of LPD rats also indicates $\mathrm{Pi}$ depletion. The importance of this calciuria is specific to the young animal (5) and accounts for the severity of Pi depletion due to an LPD in rapidly growing animals. This might be compared to the hypercalciuria observed in the $\mathrm{Pi}$ depletion of premature infants fed human milk (26). The greater sensitivity of young growing rats to an LPD compared to adult animals $(6,7,27)$ may be attributed to the fact that, for a given Pi deprivation, Pi depletion is much greater in these young growing animals. Lastly, the slight hypomagnesemia of LPD rats, without the increase in the FE of this ion that normally occurs in $\mathrm{Pi}$ depletion, suggests that these rats were also suffering from magnesium depletion.

In the HPD rats, the FE of $\mathrm{Pi}$, which was already very high, increased 2.3-fold over that of controls, whereas the Pi filtered load was not different. The QR/GFR ratio decreased by $50 \%$ in these HPD rats. This ratio was not changed by the Pi load, suggesting that the maximal transport had been reached. The increase in the GFR may help to maintain normal phosphatemia in rats on an HPD. This increase in GFR was not associated with an expansion of extracellular volume, inasmuch as neither the FE of sodium nor the arterial pressure was increased.

$B B M$ studies data. The Pi uptake by preparations of BBM vesicles shows that the $\mathrm{PCT} P \mathrm{PiR}$ is regulated by the $\mathrm{Pi}$ content of the diet during the 3rd postnatal wk, as it is in older growing rats and adult rats $(7,27-30)$. The initial rate of intravesicular accumulation was higher in LPD than in NPD rats and lower in HPD rats. As in the adult rat kidney, kinetic analyses showed that only the $\mathrm{V}_{\max }$ was modified $(7,28,31)$. The low plasma PTH may have caused the decrease in the $V_{\max }$ in the LPD rats, as PTH is known to regulate Pi transport by modifying the $\mathrm{V}_{\max }$ $(32,33)$. There was no change in the carrier affinity during adaptation of the PCT to the dietary Pi content. The Km values were identical whatever the Pi content of the diet. Thus, changing the Pi intake does not prevent this maturation.

The alteration in the number of functional units of the sodium $\mathrm{Pi}$ cotransporter or an increase in its turnover rate observed here

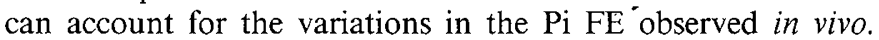
However, an LPD may stimulate the distal reabsorption of this ion in the adult (34). This cannot be excluded in the young animal, because this nephron segment is proportionally more expanded than is the PCT at this developmental stage (35).

\section{REFERENCES}

1. Steele TH, De Luca HF 1976 Influence of dietary phosphorus on renal phosphate reabsorption in the parathyroidectomized rat. J Clin Invest 57:867-874

2. Troehler U, Bonjour JP, Fleisch H 1976 Inorganic phosphate homeostasis: renal adaptation to the dietary intake and thyroparathyroidectomized rats. J Clin Invest 57:264-273 
3. Ullrich KJ, Rumrich G, Klöss S 1977 Phosphate transport in the proximal convolution of the rat kidney. I. Tubular heterogeneity, effect of parathyroid hormone in acute and chronic parathyroidectomized animals and effect of phosphate diet. Pflugers Arch 372:269-274

4. Caverzasio J, Bonjour JP, Fleisch H 1982 Tubular handling of Pi in young growing and adult rats. Am J Physiol 242:F705-F710

5. Karlen J 1989 Renal response to low and high phosphate intake in weanling, adolescent and adult rats. Acta Physiol Scand 135:317-322

6. Mulroney SE, Haramati A 1990 Renal adaptation to change in dietary phosphate during development. Am J Physiol 258:F1650-F1656

7. Neiberger RE, Barac-Nieto M, Spitzer A 1989 Renal reabsorption of phosphate during development: transport kinetics in BBMV. Am J Physiol 257:F268F274

8. Lelievre-Pegorier M, Jean T, Ripoche P, Poujeol P 1983 Transport of phosphate, D-glucose, and L-valine in newborn rat kidney brush border. Am J Physiol 245:F367-F373

9. Chen PS, Torribara TY, Warner H 1964 Microdetermination of phosphorus. Anal Chem 28:1756

10. Bailly C, Amiel C 1982 Effect of glucagon on magnesium renal reabsorption in the rat. Pflugers Arch 392:360-365

11. Schmitz J, Preiser H, Maestracci D, Ghosh BK, Cerda JJ, Crane RK 1973 Purification of the human intestinal brush border membrane. Biochim Biophys Acta 323:98-112

12. Evers C, Haase W, Murer H, Kinne R 1978 Properties of brush border vesicles isolated from rat kidney cortex by calcium precipitation. Membr Biochem 1:203-219

13. Jean $\Upsilon$, Poujeol P, Ripoche P 1981 Interactions between Na+-dependent uptake of D-glucose, phosphate and L-alanine in renal brush border membrane vesicles. Biochim Biophys Acta 647:203-210

14. Hopfer U, Nelson K, Perroto J, Isselbacher KJ 1973 Glucose transport in isolated brush border membrane from rat small intestine. $\mathrm{J}$ Biol Chem 248:25-32

15. Dahlquist A 1966 Enzymes of complex saccharide utilization intestinal disaccharidases. Methods Enzymol 8:584-591

16. Bergmeyer HU 1970 D-Glucose bestimmung mit hexokinase und glucose-6phosphat-deshydrogenase. In: Methoden der Enzymatischen Analyse. Verlag Chemie, Weinheim, Germany, pp 1163-1168

17. Hübscher G, West GR 1965 Specific assays of some phosphatases in subcellular fractions of small intestinal mucosa. Nature 205:799-800

18. Quigley JP, Gotterer GS 1969 Distribution of $(\mathrm{Na}+-\mathrm{K}+)$ stimulated ATPase activity in rat intestinal mucosa. Biochim Biophys Acta 173:456-468

19. Bradford MM 1976 Rapid and sensitive method for the quantization of microgram quantities of protein utilizing the principle of protein dye binding. Anal Biochem 72:248-252
20. Bichara M, Mercier O, Borensztein P, Paillard M 1990 Acute metabolic acidosis enhances circulating parathyroid hormone, which contributes to the renal response against acidosis in the rat. J Clin Invest 86:430-443

21. Toverud SU, Boass A, Garner SC, Endres DB 1986 Circulating parathyroid hormone concentrations in normal and vitamin $\mathrm{D}$-deprived rat pups determined with an N-terminal-specific radioimmunoassay. Bone Miner 1:145155

22. Caverzasio J, Bonjour JP 1985 Expression of chronic thyroparathyroidectomy on phosphate transport in whole kidney and proximal luminal membranes during phosphate deprivation. Pflugers Arch 405:395-399

23. Kempson SA 1985 Effects of fasting compared to low phosphorus diet on the kinetics of phosphate transport by renal brush border membranes. Biochim Biophys Acta 815:85-90

24. Bijvoet OLM 1969 Relation of plasma phosphate concentration to renal tubular reabsorption of phosphate. Clin Sci 37:23-36

25. Baylink D, Wegedal J, Stauffer M 1971 Bone formation, mineralization and resorption. J Clin Invest 50:2519-2530

26. Rowe J, Rowe D, Horak E, Spackman $\Upsilon$, Saltzman R, Robinson S, Philipps A, Raye J 1984 Hypophosphatemia and hypercalciuria in small premature infants fed human milk: evidence for inadequate dietary phosphorus. J Pediatr 104:112-117

27. Caverzasio J, Murer H, Fleisch H, Bonjour JP 1982 Phosphate transport in BBMV isolated from renal cortex of young growing and adult rats. Comparison with whole kidney data. Pflugers Arch 394:217-221

28. Cheng L, Liang CT, Sacktor B 1983 Pi uptake by renal membrane vesicles of rabbit adapted to high and low phosphorus diet. Am J Physiol 245:F175F180

29. Kempson SA, Dousa TP 1979 Phosphate transport across renal cortical brush border membrane vesicles from rats stabilized on a normal, high or low phosphate diet. Life Sci 24:881-888

30. Stoll R, Kinne R, Murer H 1979 Effect of dietary phosphate intake on phosphate transport by isolated rat renal brush-border vesicle. Biochem J 180:465-470

31. Levine BS, Ho K, Hodsman A, Kurokawa K, Coburn JW 1984 Early rena brush-border membrane adaptation to dietary phosphorus. Miner Electrolyte Metab 10:222-227

32. Gmaj P, Murer H 1986 Cellular mechanisms of inorganic phosphate transport in kidney. Physiol Rev 66:36-70

33. Kempson SA, Dousa TP 1986 Current concepts of regulation of phosphate transport in renal proximal tubules. Biochem Pharmacol 35:721-726

34. Haramati A, Haas JA, Knox FG 1983 Adaptation of deep and superficial nephrons to changes in dietary phosphate intake. Am J Physiol 244:F265F269

35. Larsson L, Aperia A, Elinder G 1983 Structural and functional development of the nephron. Acta Paediatr Scand 305:56-60 